\title{
CULTURA E NATUREZA NAS SOCIEDADES MODERNAS: ENSAIO SOBRE AS RELAÇÕES ENTRE HOMEM E NATUREZA NAS SOCIEDADES PRODUTORAS DE MERCADORIAS
}

\author{
Adriana Marques Rocha* \\ José do Egito Araújo da Mota**
}

\section{RESUMO}

O objetivo deste trabalho é entender como as sociedades em suas diferentes culturas se relacionaram com a natureza. Por esse viés objetivamos elaborar uma análise dos conceitos de cultura e natureza, especificamente nas sociedades produtoras de mercadorias. No caminho metodológico foram utilizados os conceitos de mercadoria e espetáculo, de Marx e Debord, respectivamente. Essas categorias expressam o modelo de vida dominante nas sociedades modernas. A elaboração deste ensaio compreendeu três momentos: o primeiro com a seleção e definição do objeto a ser estudado. O segundo correspondeu à revisão da literatura. O último momento foi a organização e interpretação da bibliografia selecionada, que levaram a teorizar o objeto, explicá-lo, o que possibilitou chegar às conclusões contidas nesse trabalho. Quanto à sua estrutura de exposição está constituída em quatro partes, a saber: na primeira, apresentase o objeto e justifica-se a pesquisa. Na segunda, analisa-se o conceito de cultura e especificamente de cultura da mercadoria. A terceira parte enfoca, especialmente, o conceito de natureza sob a lógica da cultura da mercadoria. E finalmente, conclui-se que sob a lógica da cultura da mercadoria a natureza é negada quando os ecossistemas são destruídos e as verdadeiras necessidades humanas são submetidas à lógica da valorização.

Palavras-chave: Cultura. Natureza. Mercadoria. Espetáculo.

\begin{abstract}
The objective of this work is to understand as the societies in your different cultures they linked with the nature. For that inclination we aimed at to elaborate an analysis of the culture concepts and nature, specifically in the societies producing of goods. In the methodological road the merchandise concepts and show were used, of Marx and Debord, respectively. Those categories express the model of dominant life in the modern societies. The elaboration of this rehearsal understood three moments: the first with the selection and definition of the object to be studied. The second corresponded to the revision of the literature. The last moment was the organization and interpretation of the selected bibliography, that they took to speculate the object, to explain to him/it, the one that made possible arrive to the conclusions contained in that work. With relationship to your exhibition structure is constituted in four parts, to know: in the first, he/she comes the object and he/she is justified the research. On Monday, the culture concept is analyzed and specifically of culture of the merchandise. The third part focuses, especially, the nature concept under the logic of the culture of the merchandise. It is finally, it is ended that under the logic of the culture of the merchandise the nature is denied when the ecosystems are destroyed and the true human needs are submitted to the logic of the valorization.
\end{abstract}

keywords: Culture. Nature. Merchandise. Show. 
Cultura e natureza nas sociedades modernas: ensaio sobre as relações entre homem e natureza nas relações sociedades produtoras de mercadorias. pp. $150-158$.

\section{INTRODUÇÃO}

"Toda a vida das sociedades nas quais reinam as modernas condições de produção se apresenta como uma imensa acumulação de espetáculos. Tudo o que era vivido diretamente tornou-se uma representação". (DEBORD,1997, p. 13).

O objeto de análise desse trabalho são os conceitos de cultura e natureza, especificamente como esses conceitos se apresentam nas sociedades produtoras de mercadorias.

Na tessitura do caminho metodológico foram utilizados os conceitos de Marx - mercadoria - e Debord - espetáculo. Por entendermos que essas categorias expressam o modelo de vida dominante nas sociedades modernas.

A elaboração deste ensaio compreendeu três momentos: o primeiro com a seleção, delimitação e definição do objeto a ser estudado. O segundo correspondeu à revisão da literatura. O último momento foi a organização e interpretação da bibliografia selecionada, que levaram a teorizar o objeto, explicá-lo, o que possibilitou chegar às conclusões contidas nesse trabalho.

Quanto à sua estrutura de exposição está constituída em quatro partes, a saber: $\mathrm{Na}$ primeira, apresenta-se o objeto e justifica-se a pesquisa. Na segunda, analisa-se o conceito de cultura e especificamente de cultura nas sociedades produtoras de mercadoria. Na terceira parte enfoca, especialmente, o conceito de natureza sob a lógica da cultura da mercadoria. E finalmente, concluise que sob a lógica da cultura da mercadoria a natureza é negada quando os ecossistemas são destruídos e as verdadeiras necessidades humanas são submetidas à lógica da valorização.

\section{CONSIDERAÇÕES METODOLÓGICAS}

"Após séculos de história de amestragem capitalista e após a imposição da relação de capital como relação mundial imediata é a mesma e única forma universal do sujeito que "encarna" o vácuo metafísico do valor idêntico em toda a parte, que constitui o Eu interior dos indivíduos como uma essência totalmente incolor e mesmo sem quaisquer qualidades, ao passo que a diferença cultural já apenas representa uma capa exterior, quase que folclórica" (KURZ, 2003).

O objetivo deste trabalho é entender como as sociedades em suas diferentes culturas se relacionaram com a natureza (CASTRO, 2010). No entanto, aqui pretendemos nos deter especificamente nos conceitos de cultura e natureza sob o viés da modernidade, ou seja, como esses conceitos se apresentam nas sociedades modernas.

Entendemos sociedades modernas as consideradas por Marx como aquelas cuja vida social se "apresenta como uma imensa acumulação de mercadorias" (MARX, 1983). Ou como diz Debord (1997) sociedades produtoras de mercadorias ou simplesmente sociedades do "espetáculo".

Compreendemos que esses conceitos (mercadoria e espetáculo) expressam a tônica reveladora da forma socioeconômica e cultural na qual vivemos, amamos, sentimos, pensamos e, por conseguinte o modo como tratamos o ambiente natural, inclusive nós mesmos.

Vale salientar, ainda que discutir cultura e natureza na contemporaneidade é uma tarefa que pressupõe desprendimento das atuais relações sociais estabelecidas, além de um olhar perscrutador na tentativa de superação de uma lógica a qual estamos submetidos quer consciente ou inconscientemente.

Nesse sentido, nossa investigação sob essas categorias nos encaminhará impreterivelmente para o interior da lógica do modo de vida dominante, isto é, da forma como produzimos e reproduzimos nossa própria vida e por sua vez a maneira como intervimos nos ambientes. 


\section{CONSIDERAÇÕES SOBRE CULTURA E SOCIEDADE}

\begin{abstract}
"[...] tudo, da política ao tráfico, das cidades à cultura, tende a produzir e reproduzir o indivíduo isolado, portanto, massificado, que se encontra em um estado de completa impotência diante do mundo que, na verdade, é o resultado de suas ações. Ele não faz outra coisa senão olhar este mundo, portanto, ser um espectador do espetáculo" (JAPPE, 2005, p. 266).
\end{abstract}

A palavra cultura desperta inúmeros sentimentos sobre o que de fato ela possa significar.

[...] o sentido da palavra latina "cultus", que deu origem ao conceito, está ligado tanto a "plantação", "agricultura" quanto a "serviço divino", "sociabilidade", "formação" e até mesmo "vestimenta" (em certas ocasiões). Essa conceituação multi-estratificada indica o caráter de integração das antigas sociedades agrárias. Os conteúdos e formas diferenciados tal qual o "metabolismo com a natureza" (Karl Marx), bem como as relações sociais e a estética não se separam entre si como "subsistemas" com "lógica própria", mas eles são sempre a expressão de um modo de existência cultural único e coerente. Em termos modernos a descrição desta existência cultural deverá soar confusamente assim: a produção era estética, a estética era religiosa, a religião era política, a política era cultural, a cultura era social e assim por diante. Em outras palavras: os atributos sociais hoje distintos para nós eram embutidos uns nos outros, cada momento da vida estava de certo modo contido nos outros (KURZ, 2010).

Assim, em termos gerais, a cultura é, pois, parte ou o próprio modo de vida em movimento (CASTRO, 2010). Sendo assim, não é possível falar de cultura como um elemento dissociado de sua época. A cultura é, portanto, "o sentido da prática total de uma formação econômico social, o seu emprego do tempo"
(DEBORD, 1997, p. 16).

Efetivamente, se nós compreendermos corretamente a cultura de uma época, compreenderemos em suas raízes o desenvolvimento do conjunto dessa época, como se tivéssemos partido da análise de suas relações econômicas (LUKÁCS,1920).

Por exemplo, a presentificação da vida, a busca incessante pelo novo, a efemeridade e instantaneidade dos momentos, a celeridade com que são definidos os desejos e o que deve ser desejado são marcas da cultura dos tempos modernos.

A novidade, o efêmero, a moda, a versatilidade dos gostos e, do mesmo modo, a necessidade de realizar adaptações freqüentes dão a impressão de viver somente o presente. A dificuldade para conceber claramente o futuro pessoal, e, portanto as incertezas a ele associadas reforçam essa ilusão de estar preso em um mundo onde o tempo desapareceu (BALANDIER, 1997, p. 249).

Por sua razão lógica, "[...] A ordem capitalista vive sob a condição de projetar continuamente um passado novo. Isto pode ser comprovado particularmente no setor propriamente cultural, onde toda publicidade periódica é dedicada ao lançamento de novidades". (DEBORD e CANJUERS, 1960). Esse fenômeno toma corpo e constata-se na própria publicidade, que instaura a ditadura do novo, do efêmero, do passageiro, 
Cultura e natureza nas sociedades modernas: ensaio sobre as relações entre homem e natureza nas relações sociedades produtoras de mercadorias. pp. $150-158$.

como frisa Bucci (2005, p. 230), "vivemos numa paisagem que elimina as distâncias e numa história que amplifica o gerúndio, presentificando o passado e o futuro".

Não é por acaso que a indústria cultural só reconhece como adequado e como elementos culturais o que pode ser reproduzido sob a forma de mercadoria. Aquilo que não puder circular sob esses moldes será considerado arcaico, antiquado, inferior ou imperfeito. Esses são alguns adjetivos utilizados para definir que isto ou aquilo não são legitimados por nossa forma inconsciente, absurda e descontrolada de produção da vida nas modernas sociedades produtoras de mercadorias.

Para Lefebvre (1991), a lógica e a estrutura desta sociedade estão ligadas à noção de duradouro, estável, enquanto os produtos e serviços comercializados representam a efemeridade, a moda passageira. Assim é que, nas sociedades modernas, "o capital precisa destruir o imaginário que ele mesmo gera de si para reconstruí-lo imediatamente a seguir. No plano do imaginário, a obsessão pelo novo é uma manifestação dessa tendência" (BUCCI, 2005, p. 225).

É nesse frenesi ditatorial da cultura mercantil que as pessoas vivem submersas, diferenciando-se da cultura de sociedades antigas ou pré-modernas. Naquelas sociedades, como salientamos acima, a cultura não se constituía como esfera separada, era parte de um todo maior, isto é, todos os momentos da vida estavam entrelaçados.

Suas atividades produtivas estavam ligadas à satisfação direta das necessidades humanas. Produziam-se artigos necessários às pessoas. Mesmo que esses artigos satisfizessem apenas as necessidades de alguns em detrimento de outros - Contudo, tudo o que era produzido tinha um fim específico, o seu uso. Em outras palavras, a satisfação das necessidades de alguma vida humana. Não importando se a necessidade era biológica - fome, sede, vestimenta - psicológica - ornamentação, ostentação, dentre outras. Aqui podemos vislumbrar detalhes que surgem como marcas indeléveis do modo de vida pré-capitalista.
Esse modo de vida era circunscrito a um determinado espaço geográfico, relacionavamse a um território concreto, particular, pertencente a um monarca ou senhor. Por desiguais que fossem aqueles modelos de sociedade alguns ou alguém usufruíam dos produtos das atividades produtivas da época, embora não se negue que havia alguns impactos ambientais resultantes, grosso modo, de suas atividades produtivas, mas nunca na proporção dos dias atuais. Kurz (2002) descreve de forma precisa aquelas condições, comparando-as com a Geografia da modernidade:

Definidas por relações de dominação e submissão no nível das relações sociais, as sociedades agrárias pré-modernas também conheceram a destruição dos nexos naturais ligada a isso. A calcarização das margens do Mediterrâneo, outrora enflorestadas, foi, como se sabe, uma consequência do consumo inescrupuloso de madeira pelas potências antigas, sobretudo pelo Império Romano. A construção de frotas de guerra desempenhou aí um grande papel. Mas essa destruição da natureza se limitava a aspectos isolados da biosfera, ela não assumia ainda um caráter sistemático e abrangente. Só a maravilhosa modernidade desencadeou uma dinâmica que se tornou de modo geral uma ameaça para a vida terrena, suscitando em grande escala aquelas "catástrofes sociais da natureza"; e com tanto maior ímpeto quanto mais a sociedade moderna se desenvolve, convertendo-se num sistema planetário total.

Nas sociedades antigas e medievais a natureza era um santuário, sagrado (CASTRO, 2010). A lógica da acumulação não fazia parte da sociedade e, portanto, a natureza, ainda que inconscientemente, era tratada com mais respeito. Enquanto que na modernidade o próprio termo sagrado passa a representar a própria forma social existente, cuja lógica e reprodução não admite questionamentos. Ao contrário, pretende-se eterna, nega todo e qualquer passado, projetando nas sociedades antigas formas arcaicas e imperfeitas de vida. Por outro lado, olha para o futuro sob os moldes do mercado e tenta sob todas as formas dominar a natureza a partir de uma segunda natureza socialmente construída. Nas sociedades modernas, o tempo morto da 
mercadoria e, portanto, da segunda natureza se pretende " ' [O tempo absoluto] [sic] imenso, sem começo nem fim. Sempre existiu e sempre existirá da mesma maneira" (ELIAS, 1998, p. 63).

Mediante essas condições podemos afirmar que a cultura que vivenciamos é a do empobrecimento de todas as instâncias da vida e do esvaziamento de todo sentido, substituído pelo sentido vazio da valorização, do culto ao mercado, da fé na metafísica concreta do fim em si mesmo da lógica do fetichismo da mercadoria.

Nessa ditadura do tempo abstrato, o tempo de vida negado é metamorfoseado em produtos, forças ameaçadoras que se colocam como substitutivos do bem-estar, qualidade de vida, da paz, da saúde, do descanso, da felicidade, do gozo e do prazer que objetivamente são suprimidos no mundo do trabalho. Essas imagens expõem a lógica do capital, como anota Bucci (2005, p. 229): "[...] os signos que se apresentam como objetos-mercadorias para promover a completude imaginária do sujeito tornam visíveis o próprio capital. Mais que isso: monopolizam o campo do visível".

Os produtos prometem a restituição do tempo perdido. A satisfação é falseada à medida que o prometido não se realiza. Cria-se com isso a necessidade de se repetir esse processo na compra de um produto. "É a realidade dessa chantagem: [...]. O consumidor real tornar-se consumidor de ilusões. A mercadoria é essa ilusão efetivamente real, e o espetáculo é sua manifestação geral". (DEBORD, 1997, p. 33). A essência de nossa cultura tem como propósito a reprodução do capital, numa sociedade onde "[...] o sujeito é o valor e a mercadoria, o dinheiro e o capital, o mercado e a concorrência" (JAPPE, 2003). Consiste, pois na adoração da forma mercadoria e na descartabilidade da vida em geral.

Em nosso modo de vida "A economia transforma o mundo, mas o transforma apenas em mundo da economia. A pseudonatureza na qual o trabalho humano se alienou exige prosseguir seu serviço infinitamente" (DEBORD, 1997, p.
30). Trata-se do desdobramento da economia espetacular, quando "tudo o que o conjunto da sociedade pode ser e fazer tornou-se mercadoria" (JAPPE, 1999, p. 36).

Assim, todas as atividades humanas participam indiretamente da valorização do capital e, por conseguinte da cultura da mercadoria. Para Lefebvre (1999, p. 23), esse fetichismo "[...] aparece como o reino da mercadoria, com sua lógica e sua ideologia, com sua língua e seu mundo".

O consumo capitalista impõe um movimento de redução dos desejos pela regularidade da satisfação de necessidades artificiais, que permanecem como necessidades sem haver sido jamais desejos -- sendo os desejos autênticos obrigados a permanecer em um estado de não-realização (ou compensados em forma de espetáculos). Moral e psicologicamente, o consumidor é na realidade consumido pelo mercado. (DEBORD e CANJUERS, 1960).

A criação desse metabolismo social é condição e condicionante da forma de produzir baseada na mercadoria, numa sociedade que tende "[...] a atomizar os homens em consumidores isolados, a proibir a comunicação. A vida cotidiana torna-se assim vida privada, domínio da separação e do espetáculo". (DEBORD, 2003, p. 146). Tudo se transforma em formas de isolamento, domínio do capital. Embebido nessa lógica o conceito de natureza emerge emoldurado por inúmeras contradições.

\section{A NATUREZA SOB O DOMÍNIO DA CULTURA DA MERCADORIA}

"A própria beleza do mundo desaparece. A economia de mercado desfigura o semblante da natureza" (KURZ, 1996).

Quando por algum motivo pronunciamos a palavra natureza nos vêm à mente a idéia de um ambiente natural, provavelmente intocado e em equilíbrio e, portanto, separado do ser humano. Todavia, tudo que a humanidade 
Cultura e natureza nas sociedades modernas: ensaio sobre as relações entre homem e natureza nas relações sociedades produtoras de mercadorias. pp. $150-158$.

realiza é, por conseguinte natureza. Sabemos ainda, que tantas foram às sociedades quanto os conceitos de natureza, haja vista cada uma dessas sociedades se apropriar ou se relacionar com a natureza de forma diferenciada (CARVALHO, 1999). Aqui se encontra provavelmente um dos pontos centrais dessa discussão: até hoje, nós nunca vivemos a natureza, apenas nos relacionamos com ela.

O relacionar pressupõe um distanciamento, separação e alienação, ainda que de modo inconsciente, mas presente em todas as sociedades que já existiram na história da humanidade. Todas essas relações eram permeadas por fetichismos, contudo, nenhum deles chegou a se tornar uma realidade para todas as sociedades existentes num mesmo momento histórico. Esse fenômeno se consumou com o advento da sociedade moderna produtora de mercadorias.

A libertação do Capitalismo significa a libertação do domínio da economia. A civilização cria, assim, o domínio humano sobre a natureza; mas, como conseqüência, o homem cai sob o domínio desses meios que havia lhe dado a possibilidade de dominar a natureza (LUKÁCS, 1920).

A natureza idealizada tornou-se opaca em meio às práticas modernas. De uma natureza objeto de temor - porque não conseguíamos compreendê-la e dominá-la em sua complexidade e imprevisibilidade - passamos a uma "segunda natureza" que põe em risco a existência da vida na Terra. Como essa passagem transcorreu? Tanto quanto a primeira natureza ou natureza natural, a segunda natureza possui rituais que the são próprios.

A cultura dos povos antigos passava inexoravelmente pelo culto às forças da terra e aos deuses correspondentes. O tempo cíclico regia as atividades necessárias à produção e reprodução da vida. E o fetichismo da natureza ou natural era determinante para as relações sociais estabelecidas.
Os povos antigos acreditavam que forças transcendentes controlavam o meio natural e, por conseguinte as vidas humanas. Nas sociedades antigas havia tempo para tudo, hoje o tempo já não nos pertence, o tempo é o tempo da produção e consumo de mercadorias, assim, ao consumirmos mercadorias somos também consumidos.

A pesquisa histórica e cultural descobriu há muito que essa definição a-histórica da experiência e da percepção do tempo não é sustentável. Reconheceu-se, antes de mais nada, que as culturas agrárias pré-modernas não pensavam num tempo linear uniforme, mas num tempo cíclico em ritmos temporais de constante repetição, regulados segundo os ciclos cósmicos e das estações. Se o tempo é uma forma inscrita a priori na capacidade cognitiva humana, não é menos verdade que a essa forma subjaz uma mudança histórica e cultural. As pesquisas mais recentes sobre as diferentes culturas do tempo confirmaram essa descoberta. Em todas essas culturas, não afetadas pela modernidade capitalista, o tempo não apenas "transcorre" de modo distinto; além disso, existem formas inteiramente diversas de tempo que transcorrem paralelamente e cuja aplicação varia de acordo com o objeto ou a esfera de vida a que se reporta a percepção temporal: "Cada coisa tem seu próprio tempo" (KURZ, 1999).

Mitos por todo o mundo foram construídos nesse sentido, mas apresentavam características distintas um do outro. Aqui temos nosso ponto de inflexão: Nas primeiras culturas existentes no mundo o culto à natureza referiase em boa medida ao medo do que essas forças naturais poderiam causar aos seres humanos e ao temor, seguido de grande respeito por compreender que a lógica da natureza era complexa, incompreensível, às vezes perigosa, mas equilibrada, perfeita. E a partir dela sobrevivência humana era possível.

Vivenciou-se nesse período uma natureza sagrada, motivo de culto, mas que paulatinamente por meio das práticas mercantis viu exorcizados todos os cultos ditos pagãos ou santos que desde então foram direcionados ao 
deus dinheiro "[sic] deixando assim desencantado o mundo, e pronto para ser formado, moldado e dominado" (THOMAS, 1989, p. 28).

Com a mudança da forma de produção da vida material, foi posta em movimento outra relação com a natureza. Baseada na extração de "valor" por intermédio da exploração das pessoas, tendo por fundamento a produção de mercadorias. Uma nova racionalidade emergia como hegemônica. Sobre as condições absurdas na relação sociedade-natureza, Debord (2008), nos anos 70 do século $X X$, emitiu sérias considerações: Mede-se e se extrapola com uma precisão excelente o aumento rápido da poluição química da atmosfera respirável, da água dos rios, dos lagos e até mesmo dos oceanos; e o aumento irreversível da radioatividade acumulada pelo desenvolvimento pacífico da energia nuclear, dos efeitos do barulho, da invasão do espaço por produtos de materiais plásticos que podem exigir uma eternidade de depósito universal, da natalidade louca, da falsificação insensata dos alimentos, da lepra urbanística que se estende sempre mais no lugar do que antes foram a cidade e o campo; [...].

De fato, a universalização da produção de mercadorias, que vem se realizando nos últimos séculos, significou, lamentavelmente, a perda da qualidade no mundo, a sua completa quantificação. O modo de vida moderno baseado no incontrolável movimento da economia mercantil introduziu, incessantemente, novos hábitos, novas rotinas e novos valores, modificando profundamente a vida social e suas relações com o ambiente. Progressivamente, os recursos naturais e as atividades humanas: fauna, flora, costumes, tempo livre, toda produção e as artes foram submetidos à lógica mercantil.

Hoje, o modo de vida moderno não se restringe a um espaço geográfico estrito, mas ao mundo todo. Pretende-se global e único. No entanto a unificação que esse modo de vida opera está em conflito direto com a natureza, ocasionando problemas tais como: o buraco na camada de ozônio, o desmatamento de florestas, assoreamento e poluição de lençóis freáticos e corpos hídricos, chuva ácida, desertificação, extinção de várias espécies animais e vegetais, derretimento das calotas polares, vazamentos de petróleo nos mares, aquecimento global, enchentes, elevação do nível dos oceanos, incidência elevada de furações e tornados, queimadas, secas, contaminação do solo, do ar, da água e alimentos por agrotóxicos e poluentes, depredação dos minérios, produção ilimitada de resíduos sólidos, produção de energia atômica cujos resíduos são tóxicos e não podem ser descartados sem que haja sérios danos à vida na Terra, dentre inúmeros outros, dentre estes a fome que atualmente atinge mais de um bilhão de pessoas.

\section{CONSIDERAÇõES FINAIS}

Tentamos mostrar nesse trabalho que na sociedade moderna cuja sociabilidade é mediada pelo dinheiro e pelo culto à mercadoria, a natureza é conflitada quando os ecossistemas são devastados para dar lugar à infra-estrutura necessária a um modelo de desenvolvimento que opta pela valorização do capital em detrimento da vida humana e do Planeta.

Esse modelo socioeconômico e cultural não só restabelece "falsamente" no plano da representação os aspectos que foram separados da vida, não só nega a natureza dos lugares, ao transformá-los em lugares para a livre circulação de mercadorias; não só priva o direito de uso do solo para a moradia e a manutenção da vida das comunidades subjugadas a todo tipo de exploração, mas submete, sobretudo, as verdadeiras necessidades humanas à lógica da valorização.

Diante dessas condições é preciso, criticamente, colocar em andamento uma mudança radical desse modelo de vida dominante, explorador e depredador que torna a vida descartável e a sociedade esquizofrênica. Um modelo de vida onde as características humanas foram transferidas para os produtos que olham a si mesmos, enquanto as pessoas não se reconhecem no outro, mas na 
Cultura e natureza nas sociedades modernas: ensaio sobre as relações entre homem e natureza nas relações sociedades produtoras de mercadorias. pp. $150-158$.

mercadoria. Um modelo de vida onde a natureza, como mercadoria moderna, ressalta o prazer liberado pelo entretenimento, exorta à necessidade de tempo livre para o contato com o verde e natural e conclama à obrigação de buscar a felicidade por intermédio das atividades que falseiam a realidade, os desejos e a forma de satisfazê-los.

Nesse sentido, esse modelo de sociabilidade e seus desdobramentos precisam ser compreendidos em sua complexidade para que sejam abolidos em sua totalidade.

\section{Bibliografia}

BALANDIER, Georges. O contorno: poder e modernidade. Tradução Suzana Martins. Rio de Janeiro: Bertrand Brasil, 1997.

BUCCI, Eugênio. O espetáculo e a mercadoria como signo In: NOVAES, Adauto (Org.). Muito além do espetáculo. São Paulo: Editora Senac São Paulo, 2005. p. 218-232.

CARVALHO, Marcos de. O que é natureza. 2. ed. São Paulo: Editora Brasiliense, 1999. (Coleção Primeiros Passos, 243).

CASTRO, Bernadete A. C. de. Notas de aula. 2010. 12 f. (Disciplina Cultura e Natureza do Programa de Doutorado da UNESP-Rio Claro).

DEBORD, Guy. O planeta doente (escrito em 1971, por Guy Debord, para aparecer no no 13 da revista Internacional Situacionista). Disponível em: $<$ http://emilianoaquino.blogspot.com/2007/11/oplaneta-doente.html >. Acesso em: 05 dez. 2008.

A sociedade do espetáculo, seguido do prefácio à 4. ed. Italiana e comentários sobre a sociedade do espetáculo. Tradução: Estela dos Santos Abreu. Rio de Janeiro: Contraponto, 1997. $238 \mathrm{p}$.

Perspectivas de modificações conscientes na vida cotidiana. In: JACQUES, Paola Berenstein (Org.). Apologia da deriva: escritos situacionistas sobre a cidade/internacional situacionista. Tradução: Estela dos Santos Abreu. Rio de Janeiro: Casa da palavra, 2003. p. 143-152.
DEBORD, Guy; CANJUERS, P. Preliminares para uma definição da unidade de um programa revolucionário. Tradução Tergiversar (Arquivo Situacionista Brasileiro). Paris, 1960. Disponível em: <www.geocities.com/projetoperiferia5/asb. htm>. Acesso em: 07 mar. 2005.

ELIAS, Norbert. Sobre o tempo. Editado por Michael Schroter. Tradução Vera Ribeiro. Revisão técnica Andrea Baher. Rio de Janeiro: Jorge Zahar Ed., 1998.

KURZ, Robert. A vitória da economia sobre a vida: crescimento econômico pode inviabilizar em pouco tempo a existência na Terra. Tradução de José Marcos Macedo. São Paulo, 1996. Disponível em: < http://www.unicamp.br/nipe/fkurtz1.htm>. Acesso em: 02 fev. 2010.

KURZ, Robert. A expropriação do tempo: falta de tempo e aceleração na cultura non-stop.1999. Disponível em:<http://obeco.planetaclix.pt/ rkurz29.htm>. Acesso em: 10 jun. 2010.

O desenvolvimento insustentável da natureza. 2002. Disponível em: <http://obeco. planetaclix.pt/rkurz108.htm >. Acesso em: 10 jan. 2009

Os fantasmas reais da crise mundial. KURZ, Robert. A guerra de ordenamento mundial. 2003. Disponível em: <http://obeco. no.sapo.pt/rkurz175.htm $>$. Acesso em: 08 jul. 2010.

KURZ, Robert. A estética da modernização: da cisão à integração negativa da arte. Tradução de Cláudio Roberto Duarte. Disponível em: < http:// obeco.planetaclix.pt/rkurz76.htm>. Acesso em: 
10 ago. 2010.

JAPPE, Anselm. Guy Debord. Tradução de Iraci D. Poleti. Petrópolis,RJ: Vozes, 1999.

. O reino da contemplação passiva. Ciclo muito além do espetáculo, Rio de Janeiro, 09 set. 2003. Disponível em: < http://anfivalorvilaboi.uoi. corn.br>. Acesso em: 30 jun. 2005

O reino da contemplação passiva In: NOVAES, Adauto (Org.). Muito além do espetáculo. São Paulo: Editora Senac São Paulo, 2005. p. 254-275.

LEFEBVRE, Henri. A vida cotidiana no mundo moderno. Tradução: Alcides João de Barros. São Paulo: ática, 1991. 216 p. (Série temas, volume 24, Sociologia e Política).
A revolução urbana. Tradução de Sérgio Martins. Belo Horizonte: Ed. UFMG, 1999. 178 p.

LUKÁCS, Gyorgy. Velha e nova cultura. Disponível em: <http://www.marxists.org/portugues/ lukacs/1920/mes/cultura.htm>. Acesso em: 20 ago. 2010.

MARX, Karl. O capital: crítica da economia política. Apresentação de Jacob Gorender. Coordenação e revisão de Paul Singer. Tradução de Régis Barbosa e Flávio R. Kothe. Vol. 1, livro primeiro. O processo de produção do capital. tomo 1 (prefácio e capítulos I a XII). São Paulo: Abril Cultural, 1983. (Os economistas)

THOMAS, Keith. O homem e o mundo natural. São Paulo: Cia. das Letras, 1989. 